\title{
Analysis of Steel Connections to Resist Progressive Collapse
}

\author{
Yanglin Gong, Chen Zhang, Jian Deng \\ Department of Civil Engineering, Lakehead University, Thunder Bay, Canada \\ Email: ygong@lakeheadu.ca
}

How to cite this paper: Gong, Y.L., Zhang, C. and Deng, J. (2019) Analysis of Steel Connections to Resist Progressive Collaps. World Journal of Engineering and Technology, 7, 10-20.

https://doi.org/10.4236/wjet.2019.72B002

Received: February 19, 2019

Accepted: May 14, 2019

Published: May 17, 2019

\begin{abstract}
This paper presented a methodology for the analysis and design of steel connections under a double-span connection within the context of preventing progressive collapse. First, various connection models were described and their pros and cons were provided. Then, the load-displacement characteristics of a component-based spring model were described. Thirdly, an experimental study on the behaviors of shear tab connections under tension was presented. The main sources of the deformation capacity of the shear tab connections were identified. Finally, a design example of a shear tab connection was provided to illustrate the methodology.
\end{abstract}

\section{Keywords}

Steel, Steel Connections, Shear Tab Connection, Progressive Collapse, Connection Robustness

\section{Introduction}

Progressive collapse is referred to a localized failure, due to an unexpected event such as an accidental blast, causes the failure of adjoining structural elements, which in turn spread further resulting in the collapse of the entire structure or a disproportionally large part of it. Since the collapse of World Trade Centre twin towers in 2001, structural design to resist progressive collapse has garnered tremendous attentions from civil engineering community. The DoD guideline [1] was the very first rigorous criteria on the design of buildings to resist progressive collapse. A recent Canadian standard [2] also reflected many new developments in this field. Both direct and indirect approaches to resist progressive collapse have been outlined in these guidelines with various levels of details and effectiveness.

The alternate load path method, a direct design approach where in a build- 
ing's integrity and robustness are assessed under a condition of instantaneous loss of a column or a wall, has become a commonplace in the design of buildings to resist progressive collapse. In this methodology, a building is mainly subjected to service gravitational loads while one of the columns is assumed to be removed (Figure 1). The design objective is to ensure that the building structure is capable of bridging the resulting double-span condition in order to arrest the local failure.

Traditionally, steel connections are designed for a shear force only (for a simple connection) or a shear force plus a bending moment (for a semirigid or rigid connection). The rotational ductility demand for the connections is not greater than 0.03 radians under gravity loads [3] and not greater than 0.05 radians under earthquake events [4]. However, under a double-span condition, the primary strength action on the affected connections is catenary tensile force (as shown in Figure 1) and the moment and shear actions become secondary, while the rotational ductility demand on the connections could reach as large as 0.10 radians [5] [6]. In particular, a shear or semi-rigid connection is usually the weakest link in the loading path of bridging the removed column. Thus, the robustness design of the connections plays a critical role to the overall integrity of the structure. Gong [6] was among the first to point out that the supply of connection ductility is at the core of connection robustness design. Gong [6] further suggested that the capacity design principle, a method commonly adopted in seismic design, should be applied to connection detailing for ductility supply.

This paper is the continued efforts by the authors on the nonlinear modelling of connections in the context of robustness design of steel structures. First, this paper presents a general component-based model for steel connections. Next, an experimental and numerical study on shear tab connections are provided as an example on how to obtain the strength and stiffness of connection components. Finally, an analysis and design example is given on a shear tab connection under the removal of a middle column.

\section{Analytical Models of a Steel Connection}

A simple or semi-rigid steel connection will be loaded well into its inelastic stage under a double-span condition. On the one hand, as the weakest link in the load path, the steel connection could be loaded to a failure mode of material rupture. On the other hand, in order to facilitate the development of a catenary action among the bridging beams, it is necessary to design the steel connection such that it is capable of undergoing large inelastic deformation before failure. Thus, a connection model must capture the plastic behaviors of the connection.

There are three types of analytical models for a connection. The first one is called a hinge model, as illustrated by the connection model on the right side of the middle column in Figure 2(b). The hinge model is a dimensionless point (before loading) with a rotational stiffness and an axial stiffness, in which the two stiffnesses are obtained without texplicitly considering the interaction 


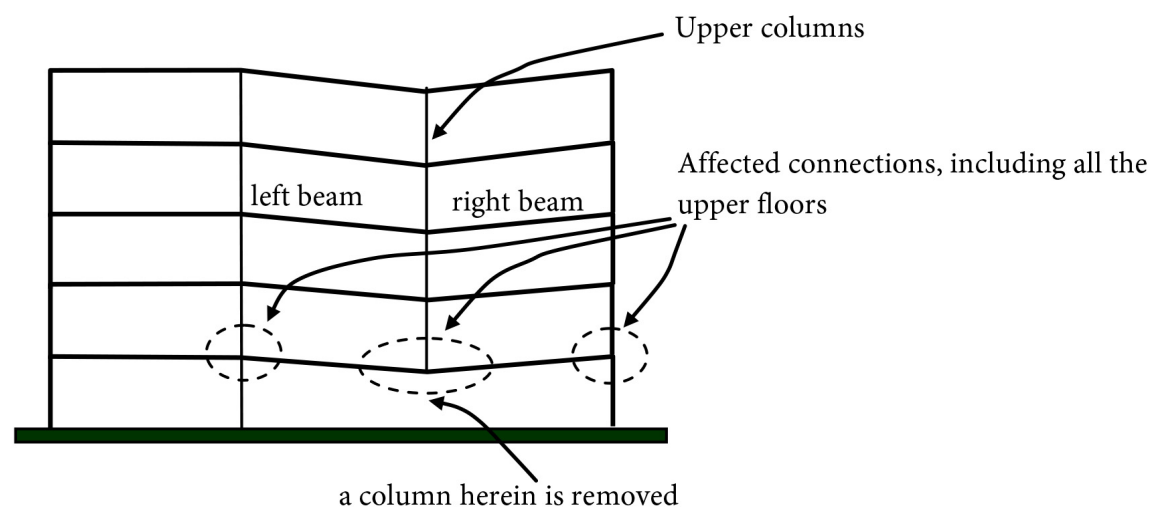

(a) removal of a column

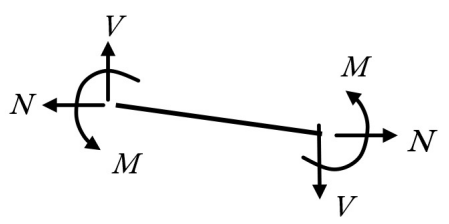

(b) End forces of a beam

Figure 1. A double-span condition.

between the rotational and axial deformations. The second one is called component-based model, as shown by the left SIDE of the middle column in Figure 2(b), in which a connection is represented by a set of related springs. Each spring captures individual behavior of a connection component, such as a bolt, a beam web, an angle, a hole bearing or a combination of them. The third type is a finite element model.

The hinge model is the easiest one to use with the least computational efforts, but it also possesses the least accuracy. A component-based model is more laborious than a hinge model, but it is still far simpler to use than a finite element model. The component-based model will be adopted in this study, and the finite element model will be used to aid the development of the component-based model.

\subsection{Component-Based Connection Model}

A component-based model uses springs to capture various sources of displacement from connection components. The methodology was originated in Europe and is gaining acceptance in North America. Figure 2 uses a shear tab connection (also called a single-plate simple connection) to illustrate such a model. Figure 2(a) shows that the lower story of a middle or interior column is removed and the beam-to-column shear connections possess three bolt rows. Figure 2(b) shows that the shear tab connection at the left side of the middle column is replaced by three parallel uniaxial springs corresponding to the three bolts, while the depth of the beam is modelled using a rigid arm at the beam end. Due to the sagging of the middle column under gravitational loads, these springs 


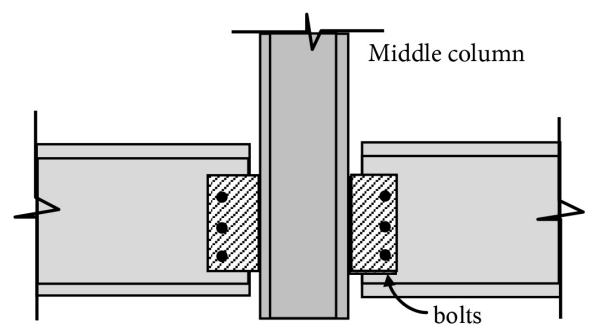

(a) shear tab beam-to-column connections

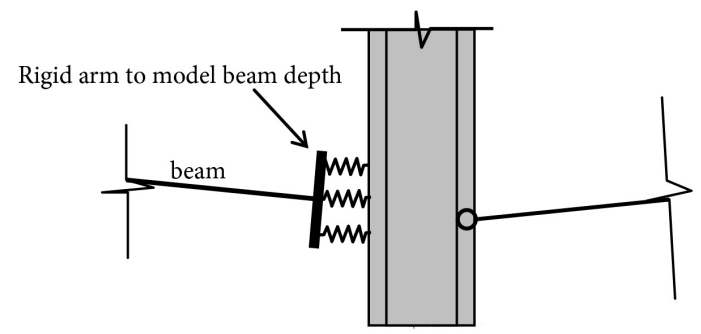

(b) component-based model and hinge model

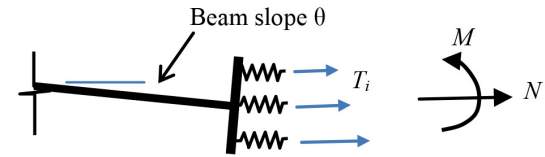

(c) spring forces and connection force resultants

Figure 2. Modelling of steel connections.

experience axial deformation and thus develop axial force, as illustrated by force $T_{i}$ in Figure 2(c). The resultants of these individual spring forces are the connection axial force $N$ and moment $M$ (also see Figure 1(b)), i.e., the interaction between $N$ and $M$ are accounted for. Note that the connection shear force $V$ is not shown in Figure 2 as the shear displacement is usually secondary. But the shear displacement can be easily included into the connection model by adding shear spring in vertical direction if necessary. Because the parallel springs are corresponding to the bolts over the length of the tab (or over the depth of the beam), such a component-based model is capable of capturing an arch action, if existing, within the bridging beams. On the contrary, a hinge connection model is unable to capture arch action due to its zero dimension in vertical direction.

\subsection{Component Spring Model}

In Section 2.1, a connection is modeled by several parallel uniaxial springs. A priori knowledge about the mechanical properties of the spring, i.e., the relationship between its deformation $\Delta$ and its force $T$, is needed for the analysis of the steel connection.

In general, apiece-wise linear curve, as shown in Figure 3, can be adopted for the $T-\Delta$ curve, where $T_{y}$ and $T_{u}$ are the tensile yielding and the ultimate strength of the spring, respectively, with $\Delta_{y}$ and $\Delta_{u}$ being their corresponding tensile deformations. Beyond $\Delta_{u}$, the falling segment represents the stage of propagation 


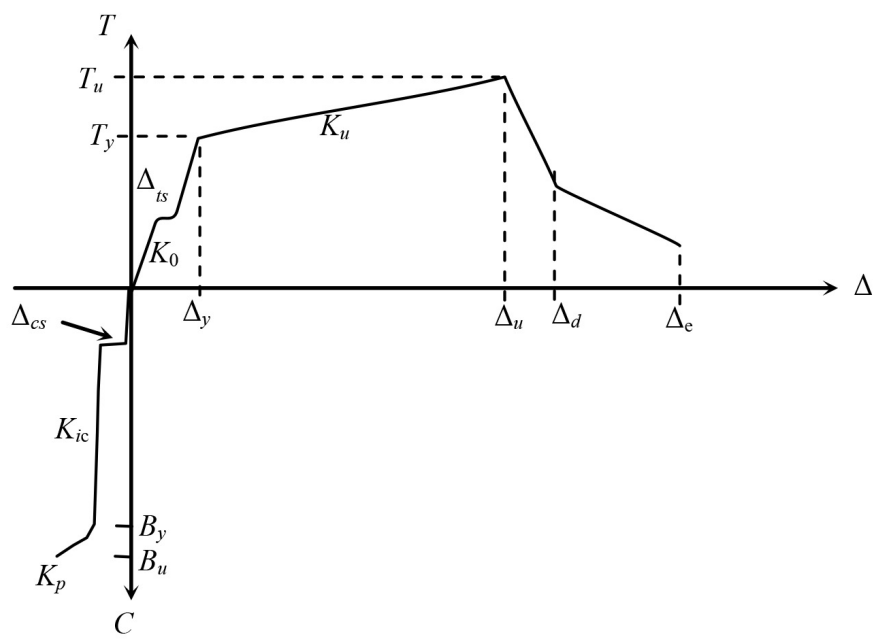

Figure 3. Load versus deformation of a nonlinear spring.

of material rupture, a stage is typically ignored in conventional structural design but could still play an important role in the structural bridging under a double-span condition. The ratio of $\Delta_{u} / \Delta_{y}$ indicates the inelastic axial ductility of the spring. $\Delta_{t s}$ is the bolt slippage deformation for bolted connections. A negative value of $\Delta$ in Figure 3 represents a compressive deformation of the spring. $\Delta_{c s}$ denotes bolt slippage under the compressive load. A compressive $C-\Delta$ curve ( $T$ is replaced by compression $C$ in Figure 3) is necessary if the arch action is of concern. Notations $B_{y}$ and $B_{u}$ are yielding and ultimate compressive strengths, respectively. Notation $K$ denote tangential stiffness at various force level.

The evaluation of $T-\Delta$ curve can be tedious due to its nonlinear nature. Standards such as [1] [2] provide empirical curves for some types of steel connections. For this paper, we use shear tab connection as the example to demonstrate how to obtain such a curve.

\subsection{Shear Tab Connections}

In this section, a study to obtain the force versus deformation curve of shear tab connections is used to illustrate the typical behaviors of steel connections. As shown in Table 1, a pure tension test of ten shear tab connection specimens is conducted herein. Figure 4 shows the design of the specimens. The connection geometry adopted typical north American practice. The tab plate was welded to a $50 \mathrm{~mm}$ thick anchoring plate, which was in turn fixed to a loading head during tensile test. Each specimen was named a unique ID as follows: the first letter T represents tab connection, followed by the thickness of the tab in $\mathrm{mm}$, then the edge distance of the bolt holes, then the number of bolt columns, and the last, the specimen number. For example, specimen T95-45-1a had a tab thickness of $9.5 \mathrm{~mm}$, edge distance of $45 \mathrm{~mm}$, one-column of bolts, and the first specimen of the kind. Specimen T127-45-2b had a tab thickness of $12.7 \mathrm{~mm}$, edge distance of $45 \mathrm{~mm}$, two-column of bolts, and the second specimen of the kind. The ASTM A490 bolt diameter was $22.2 \mathrm{~mm}$, and the hole diameter was $23.8 \mathrm{~mm}$. Tab 
Table 1. Shear tab connection speciemns.

\begin{tabular}{cccc}
\hline \multirow{2}{*}{ Specimen ID } & \multicolumn{3}{c}{ Table Column Head } \\
\cline { 2 - 4 } & Deformations & Tensile strengths & Failure mode \\
\hline T95-45-1a, 1b & $2.0,11.5,18.3$ & $350,430,200$ & Shear of hole edge \\
T95-57-1a, 1b & $2.5,14.2,17.0$ & $375,488,250$ & Tension rupture at net section \\
T95-45-2a, 2b & $1.7,5.8,8.8$ & $425,480,150$ & Tension rupture at inner net section \\
T127-45-1a, 1b & $1.9,9.8,17.0$ & $440,535,107$ & Shear of hole edge \\
T127-45-2a, 2b & $2.3,5.5,9.0$ & $570,638,200$ & Tension rupture at inner net section \\
\hline
\end{tabular}

Note: the notations of deformations and strengths are given in Figure 3. Residual strength $T_{d}$ is defined as the strength corresponding to $\Delta_{d}$ The bolt slippage $\Delta_{t s}$ were excluded from $\Delta_{\mathrm{y}}, \Delta_{\mathrm{u}}$ and $\Delta_{\mathrm{d}}$ in this table.

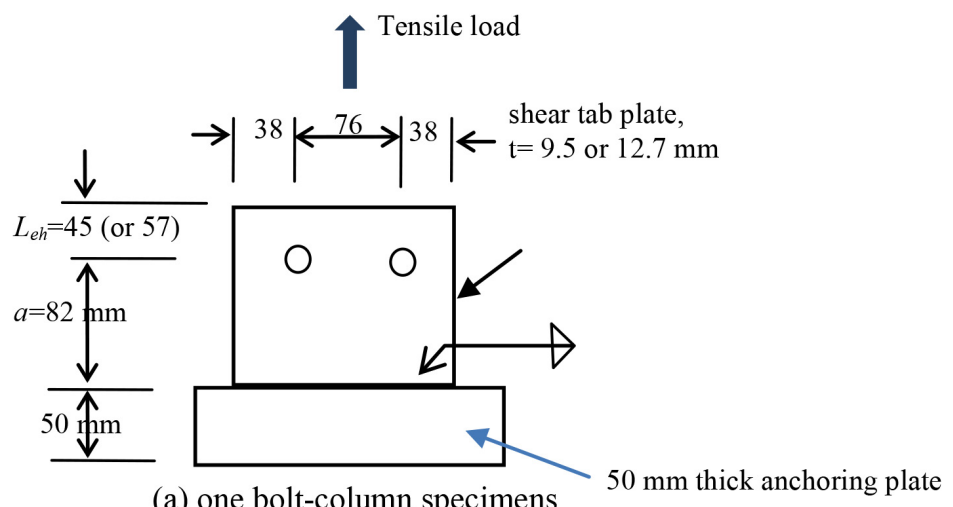

(a) one bolt-column specimens

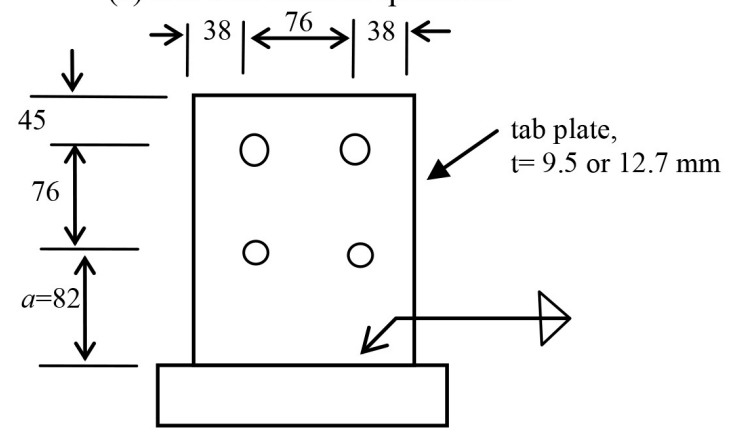

(b) two bolt-column specimens

Figure 4. Design of shear tab specimens.

materials were CSA/G40.21 $300 \mathrm{~W}$ steel, and the measured strengths were: yield strength $F_{y}=376 \mathrm{MPa}$ and ultimate tensile strength $F_{u}=490 \mathrm{MPa}$ for $9.5 \mathrm{~mm}$ thick tab; $F_{y}=387 \mathrm{MPa}$ and $F_{u}=495 \mathrm{MPa}$ for $12.7 \mathrm{~mm}$ thick tab. The sizes of the welds and bolts were chosen based on a capacity design principle such that rupture failures of the welds and bolts would not occur during the test.

The observed failure modes are shown in Figure 5. The measured specimen strengths and deformations are provided in Table 1. The load-deformation curves of typical specimens are given in Figure 6. As expected, the welds and bolts did not fail during the test. The specimens having an edge distance of 45 $\mathrm{mm}$ and one column of bolts experienced shear rupture at the hole. Other 

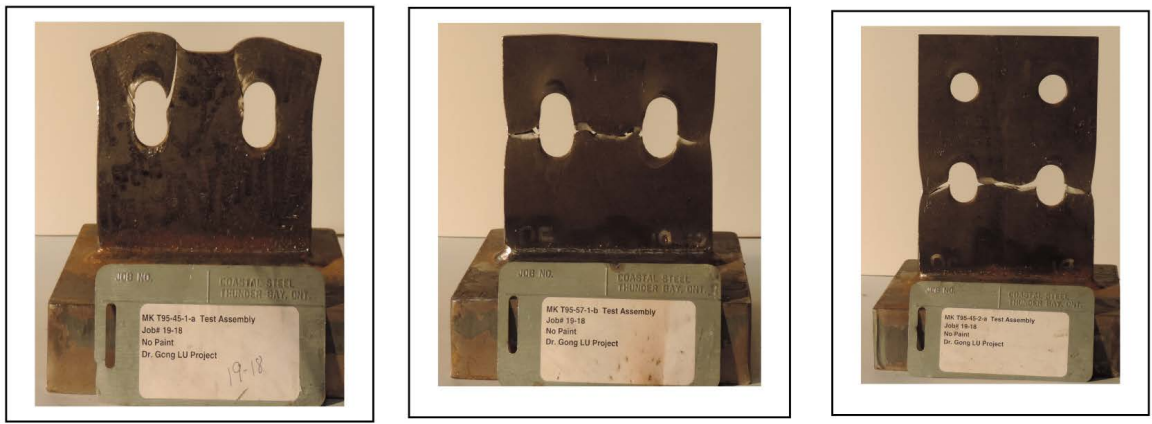

Figure 5. Failure modes of shear tab specimens under tensile load.

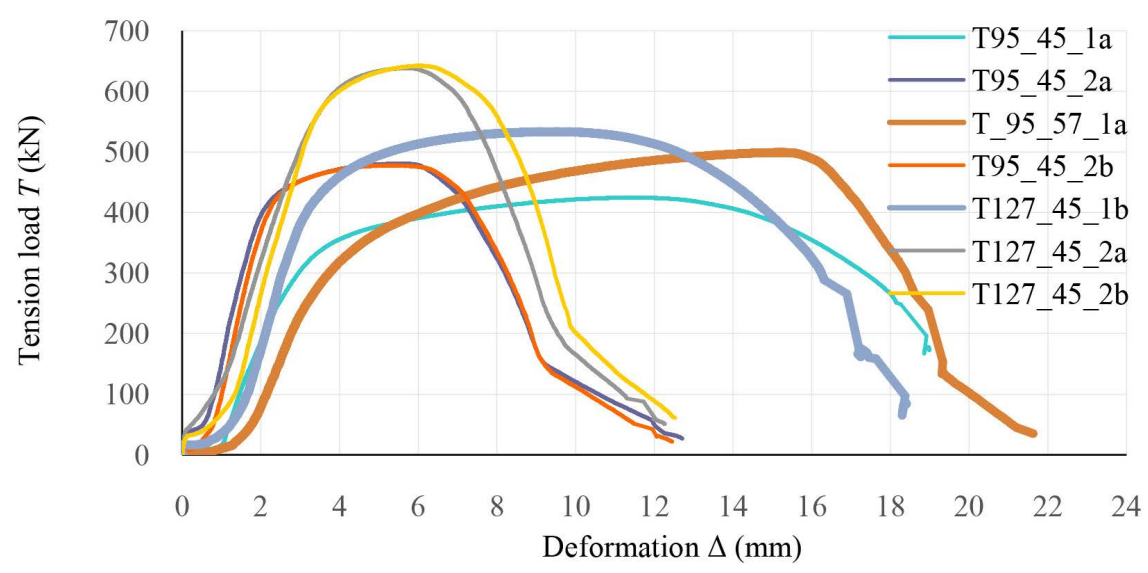

Figure 6. Load versus deformation curves of the specimens.

specimens experienced tension rupture at the net section of boltline. A careful examination of the tested specimens found that the main components of deformation $\Delta$ are: 1) bolt slippage inside the bolt holes, which could reach as much as $2.5 \mathrm{~mm}$. Since the specimens used snug-tightened bolts, the slippage occurred at the beginning of the loading (Figure 6);2) bearing of holes, as indicated by the shrinkage of the hole edge and the enlargement of the hole diameter; 3 ) bending of hole edge for the specimens having $L_{e h}=45 \mathrm{~mm}$; 4) shear yielding and tearing of holes along the shear plan for the specimens having $L_{e h}=45 \mathrm{~mm}$; and 5) yielding and necking of net section under tension for the specimens having $L_{e h}=57 \mathrm{~mm}$ or having two columns of bolts. Table 2 provides the measured residual deformations.

The comparison between T95-45 and T95-57 indicates that increasing the edge distance from $2 d_{b}(45 \mathrm{~mm})$ to $2.5 d_{b}(57 \mathrm{~mm})$ resulted in a larger tensile resistance without decreasing the overall deformation capacity. But edge distance appears has no impact on the initial tensile stiffness. Comparing T95-57-1 with T95-45-2, one can see that two-column of bolts did not increase tensile resistance (both groups had the same failure mode), but reduced deformation capacity approximately by half (due to the smaller bearing deformation).

To aid the development of an accurate $T-\Delta$ curve of the spring model for various tab thickness and bolt diameters, more test data are needed. To this end, a 
Table 2. Components of tensile deformation $\Delta_{d}$.

\begin{tabular}{cccccc}
\hline & \multicolumn{5}{c}{ Table Column Head } \\
\cline { 2 - 6 } Specimen ID & $\begin{array}{c}\text { Test residual } \\
\text { deformation } \\
(\mathrm{mm})\end{array}$ & $\begin{array}{c}\text { Hole bearing } \\
\Delta_{h b}(\mathrm{~mm})\end{array}$ & $\begin{array}{c}\text { Hole bending } \\
\Delta_{h n}(\mathrm{~mm})\end{array}$ & $\begin{array}{c}\text { Shear } \\
\text { tearing } \\
\Delta_{s t}(\mathrm{~mm})\end{array}$ & $\begin{array}{c}\text { Necking } \\
\Delta_{n k}(\mathrm{~mm})\end{array}$ \\
\hline T95-45-1 & 17.0 & 4.0 & 9.5 & 4.0 & 0 \\
T95-57-1 & 17.0 & 7.0 & 1.0 & 0 & 9.0 \\
T95-45-2 & 8.0 & 1.0 & 0 & 0 & 7.0 \\
T127-45-1 & 15.0 & 2.0 & 10.0 & 3.0 & 0 \\
T127-45-2 & 8.0 & 1.0 & 0 & 0 & 7.0 \\
\hline
\end{tabular}

Note: the bolt slippage is excluded from the deformations.

finite element model is developed to mimic the tested specimens. Then, the verified finite element model is used to conduct a parametric study to expand the database of the test results, including taking into account the combined effect of shear load and tensile force.

The finite element software package Abaqus is used for this study, with Abaqus/standard used as the analysis engine [7]. The three-dimensional brick element with eight nodes is used. The material properties included elastic modulus $E=200 \mathrm{GPa}$, Poisson's ratio of 0.3 , the calibrated initial fracture strain as a function of triaxiality, and the calibrated damage evolution criterion as a function of the plastic displacement of an element. Figure 7 illustrates that the finite element model is capable of replicating the two failure modes. In the figure, only one-half of the specimens was required to be reproduced due to the symmetry of the specimens. The finite element models allow the accurate measurement of bearing and necking deformations. More details about the finite element model ling will be reported in another paper.

\section{Analysis Example of a Shear Tab Connection}

Figure 8 shows a part of a building floor framing plan with a panel dimension $9.15 \mathrm{~m}$ by $9.15 \mathrm{~m}$. The shape of Girder $G_{1}$ is W610 $\times 125$ [8], with beam depth $d$ $=612 \mathrm{~mm}$, web thickness $t_{w}=11.9 \mathrm{~mm}$, expected yielding strength $F_{y e}=385$ $\mathrm{MPa}$ and ultimate strength $F_{u e}=495 \mathrm{MPa}$. The column section is W360 $\times 347$, with its depth of $d_{c}=407 \mathrm{~mm}$, flange width $b_{c f}=404 \mathrm{~mm}$. The connections of concern are at the ends of girder G1. For the double-span condition shown, the design floor load for the girder is estimated to be $2.4 \mathrm{kPa}$ considering the composite floor slab itself is capable of sustaining part of the floor weight. Using the tributary area of the central column, we can find that the double-span beams must be capable of supporting $133 \mathrm{kN}$ point load at the central column.

The simple connections between girder G1 and the columns are $12.7 \mathrm{~mm}$ thick tab plate, with five diameter $22.2 \mathrm{~mm}$ high-strength bolts and diameter $23.8 \mathrm{~mm}$ standard holes. The tab plate length is $380 \mathrm{~mm}$. The edge distance is 57 $\mathrm{mm}$, and the distance between the bolt line and the weld line is $80 \mathrm{~mm}$. The 


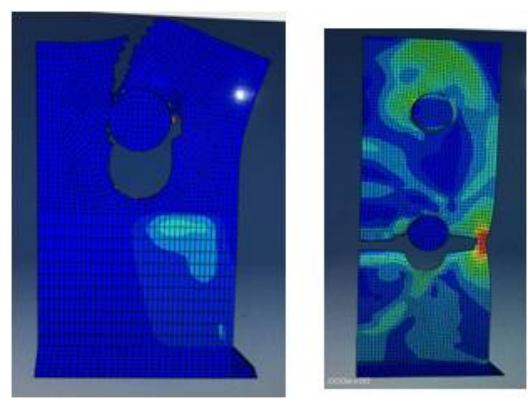

Figure 7. Finite element models of one-half of the specimens.

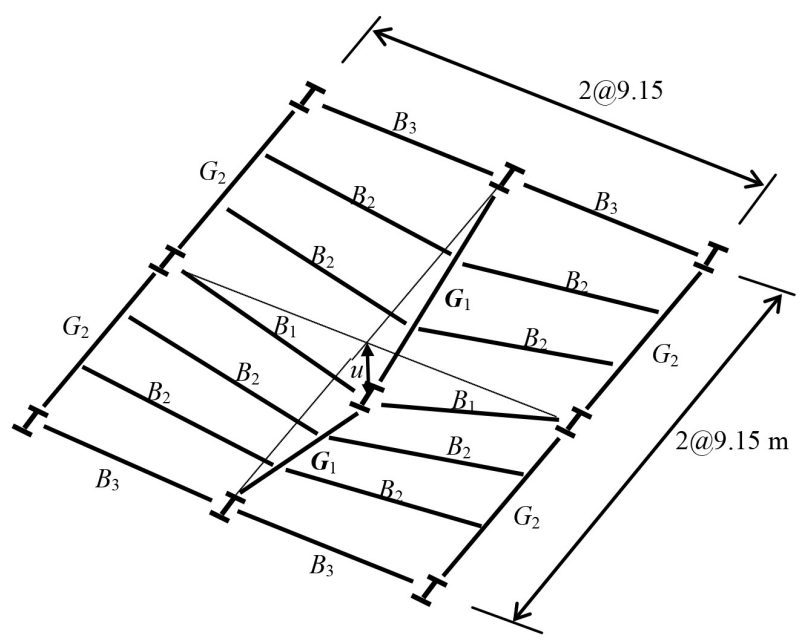

Figure 8. Floor framing plan of a design example.

center of the connection coincides with the centerline of the girder. The connection spring model is based on a tributary width of $76 \mathrm{~mm}$ and edge distance of $2.5 d_{b}$. The parameters of the $T-\Delta$ curve (Figure 3 ) of the springs are provided as follows: 1) a bolt slippage of $\Delta_{t s}=1.6 \mathrm{~mm}$ at the beginning with zero loading; 2) $\Delta_{y}=4.1 \mathrm{~mm}, \Delta_{u}=19.6 \mathrm{~mm}$ and $\Delta_{d}=22.6 \mathrm{~mm}$, corresponding to strength $T_{y}$ $=250 \mathrm{kN}, T_{u}=325 \mathrm{kN}$ and $T_{d}=166 \mathrm{kN}$, respectively. The bolt holes at the beam web connection must be proportioned for a load of $325 \mathrm{kN}$ such that the resistance of the shear failure at the hole edge will not govern (which results in an edge distance of $65 \mathrm{~mm}$ for the beam web holes). It is assumed that the springs cannot take any compressive force, thus, compressive strength $B_{y}$ and $B_{u}$ are not required.

The shear tab is modeled by 5 springs, and the locations of the springs with respect to the centroid of girder G1 are $\mathrm{y}_{1}=152 \mathrm{~mm}, \mathrm{y}_{2}=76 \mathrm{~mm}, \mathrm{y}_{3}=0, \mathrm{y}_{4}=$ $-76 \mathrm{~mm}$, and $\mathrm{y}_{5}=-152 \mathrm{~mm}$ (positive below the beam centroid and negative above the beam centroid). The axial deformation of the $i^{\text {th }}$ spring is calculated as

$$
\Delta_{i}=\left(L_{b} / 2\right)[(1 / \cos \theta)-1]+y_{i} \tan \theta
$$

where: $\theta$ is girder slope (Figure 2(c)); $L_{b}=8716 \mathrm{~mm}$, which is the length of the girder (note that the connections at the two ends of the girder are identical). The 
first term of Equation (1) represents the elongation caused by the sagging of the middle column; i.e., the difference of the lengths between the hypotenuse and the horizontal side. The second term is the deformation caused by the rigid arm rotating with the girder. The deformation of the girder under axial load is negligible.

The load-carrying resistance of the double-span beams at its ultimate limit state is $P_{u}=164 \mathrm{kN}$, while the beam slope $\theta=0.072 \mathrm{rad}$. The corresponding deformation of each spring are: $\Delta_{1}=22.3 \mathrm{~mm}, \Delta_{2}=16.8 \mathrm{~mm}, \Delta_{3}=11.3 \mathrm{~mm}, \Delta_{4}=$ $5.8 \mathrm{~mm}$, and $\Delta_{5}=0.4 \mathrm{~mm}$; the tensile force of each spring are: $T_{1}=183 \mathrm{kN}, T_{2}=$ $311 \mathrm{kN}, T_{3}=285 \mathrm{kN}, T_{4}=258 \mathrm{kN}$, and $T_{5}=0$ due to bolt slip. The connection force resultants are: axial force $N=1037 \mathrm{kN}$, moment $M=32 \mathrm{kN}-\mathrm{m}$, shear force $V=82 \mathrm{kN}$. The sagging of the middle column is $L_{b} \tan \theta=628 \mathrm{~mm}$.

Though it is not conducted herein, additional angle connections can be added to the top and bottom flanges of the beam to further increase the strength and ductility of the beam-to-column joint [5].

\section{Summary and Conclusions}

The beam-to-column shear connections are the weakest link of a floor system to bridge are moved column known as a double-span scenario. To develop a catenary action within the double-span beams under the sagging of the floor, the connections must be capable of sustaining large axial deformation in addition to the rotation. A nonlinear connection model is required for evaluating the demands on the steel connections. To this end, this study presented a component-based spring model, which is also able to capture the interaction between the axial and rotational deformations of the connections. An experimental study on shear tab connections were conducted, and finite element models were verified in order to expand the test data. The obtained load versus deformation curves were applied to an analysis example. The presented procedure is applied to the robustness design of steel building frameworks using alternate path method [1].

\section{Acknowledgements}

The authors wish to acknowledge the financial supports from Coastal Steel Construction Ltd., Thunder Bay, Ontario, Canada.

\section{Conflicts of Interest}

The authors declare no conflicts of interest regarding the publication of this paper.

\section{References}

[1] DoD. UFC 4-023-03 (2016) Design of Buildings to Resist Progressive Collapse, Change 3. Department of Defense, Washington DC.

[2] CSA Group (2012) S850-12 Design and Assessment of Buildings Subjected to Blast 
Loads. ISBN 978-1-55491-824-9, Mississauga.

[3] Gong, Y. (2008) Double-Angle Shear Connections with Small Hollow Structural Section Columns. Journal of Constructional Steel Research, 64, 539-549. https://doi.org/10.1016/j.jcsr.2007.11.006

[4] Xu, L., Gong, Y. and Grierson, D.E. (2006) Seismic Design Optimization of Steel Building Frameworks. Journal of Structural Engineering, ASCE, 132, 277-286. https://doi.org/10.1061/(ASCE)0733-9445(2006)132:2(277)

[5] Gong, Y. (2017) Test, Modeling and Design of Bolted-Angle Connections Subjected to Column Removal. Journal of Constructional Steel and Research, 139, 315-326. https://doi.org/10.1016/j.jcsr.2017.10.004

[6] Gong, Y. (2010) Analysis and Design for the Resilience of Shear Connections. Canadian Journal of Civil Engineering, 37, 1581-1589. https://doi.org/10.1139/L10-097

[7] Abaqus Analysis User's Guide. (2019) http://130.149.89.49:2080/v6.14

[8] CISC (2016) Handbook of Steel Construction. 11st Edition, Canadian Institute of Steel Construction, ISBN 978-0-88811-176-0. 